\title{
INFLUÊNCIA DO PROJETO PEDAGOGIA AMBIENTAL DE SUAPE NAS PRÁTICAS PEDAGÓGICAS AMBIENTAIS DE PROFESSORES DAS REDES PÚBLICAS DE ENSINO NOS MUNICÍPIOS DE CABO DE SANTO AGOSTINHO E IPOJUCA (PE)
}

José Roberto Carvalho Zaponi ${ }^{1}$

Sonia Pereira Valéria ${ }^{2}$

José Ricardo Barbosa da Silva ${ }^{3}$

Resumo: Este trabalho investigou a influência das atividades pedagógicas de Educação Ambiental por meio de cursos e oficinas executadas pelo Projeto Pedagogia Ambiental do Complexo Industrial Portuário Governador Eraldo Gueiros - Suape nas práticas didáticas de professores dos municípios do Cabo de Santo Agostinho e Ipojuca em Pernambuco. Obtiveram-se os dados por meio de questionário, sendo tabulados e convertidos em números relativos. Os resultados demonstraram que as atividades educativas influenciaram positivamente $87 \%$ dos entrevistados, que incluíram práticas ambientais em sala de aula. Diversos outros pontos apontaram benefícios para as atividades profissionais dos entrevistados.

Palavras-chave: Coleta Seletiva; Educação Ambiental; Ensino-Aprendizagem; Responsabilidade Socioambiental; Porto de Suape.

\footnotetext{
${ }^{1}$ Programa de Pós Graduação em Tecnologia Ambiental do Instituto de Tecnologia de Pernambuco (ITEP-OS). E-mail: roberto.zaponi@gmail.com

2 Programa de Pós Graduação em Tecnologia Ambiental do Instituto de Tecnologia de Pernambuco (ITEP-OS). E-mail: soniaitep@gmail.com

3 Universidade Federal de Pernambuco, sou aluno de doutorado do Programa de Pós-Graduação em Biologia Vegetal.E-mail: ricardosilva@suape.pe.gov.br
}

Revbea, São Paulo, V. 12, No 2: 318-330, 2017. 


\section{Introdução}

Assim como os diversos ramos pedagógicos mais recentes, a Educação Ambiental (EA) tem ao longo das últimas décadas amadurecido tanto do ponto de vista mundial como no cenário nacional. Durante esse amadurecimento, instituíram-se diversos eventos, legislações e demais formalidades sempre com o fim de estimular a progressão da EA e o intuito de dar subsídio à melhoria da conduta humana por meio da educação. Dentre os diversos marcos na trajetória da EA, podem-se destacar:

$\mathrm{Na}$ década 1860, dois grandes marcos - o contundente ensaio de Thomas Huxley sobre a interdependência dos seres vivos, Evidências sobre 0 lugar do homem na natureza, em 1863; e a publicação em 1864 do livro $O$ homem e a natureza: ou geografia física modificada pela ação do homem do diplomata George Perkin Marsh (DIAS, 2004, p. 75).

- Após quase cem anos, lançou-se na década de 1960 o livro Primavera silenciosa, escrito pela jornalista Rachel Carson, que marcou o início de uma revolução em defesa do meio ambiente (MURPHY, 2005, p. 1).

- Em 1972, importante marco decorrente da articulação do Clube de Roma foi a publicação intitulada Limites do crescimento, obra que questiona a forma do crescimento populacional humano (JACOBI, 2003, p. 193); e a criação do Programa das Nações Unidas para o Meio Ambiente - Pnuma (MORAES et al., 2012, p. 95).

- Em 1975, a Organização das Nações Unidas para a Educação, Ciência e Cultura (Unesco) promoveu, em Belgrado, ex-lugoslávia, um encontro internacional sobre Educação Ambiental, onde criou o Programa Internacional de Educação Ambiental (Piea). Esse programa propõe que ela deve ser contínua, multidisciplinar, integrada às diferenças regionais e voltada para os interesses nacionais (DIAS, 2004, p. 38).

- A Conferência Intergovernamental de Educação Ambiental em Tbilisi, Geórgia, ex-URSS, organizada pela Unesco com a colaboração do Pnuma em 1977, configura-se como evento decisivo, quando se elaboraram os importantes objetivos, princípios, estratégias e recomendações para a Educação Ambiental (DIAS, 2004, p. 39).

- No Brasil, o Plenário do Conselho Federal de Educação aprova por unanimidade a Câmara de Ensino, a respeito do parecer n.․ 226/87, que considera necessária a inclusão da Educação Ambiental dentre os conteúdos a serem explorados nas propostas curriculares das escolas do 1.으 e 2.․ graus (DIAS, 2004, p. 44).

- Em agosto de 1987, na cidade de Moscou, ex-URRS, realizou-se o Congresso Internacional da Unesco-Pnuma sobre a Educação e a Formação Ambiental relativas ao meio ambiente, que produziu um documento denominado Estratégia internacional de ação em matéria de educação e formação ambiental para o decênio de 1990 (DIAS, 2004, p. 45).

- A EA torna-se obrigação nacional na Constituição brasileira de 1988. 
- Em 1991, a Portaria n. 678/91 do Ministério da Educação (MEC) determina que os sistemas de ensino devem contemplar a Educação Ambiental em todas as instâncias, níveis e modalidades, o que foi uma grande vitória para a formalização da EA no ensino formal (DIAS, 2004, p. 49).

- A proposta do Programa Nacional de Educação Ambiental (ProNEA), em 1994, promoveu a articulação das ações educativas voltadas às atividades de proteção, recuperação e melhoria socioambiental, além de potencializar a função da educação para as mudanças culturais e sociais (BRASIL, 2005, p. 25).

- A assinatura do Tratado de Educação Ambiental para Sociedades Sustentáveis e Responsabilidade Global, estabelecido em 1992, remete a Educação Ambiental como um processo dinâmico em permanente construção (JACOBI, 2003, p. 194). Tornou-se referência a realização da Educação Ambiental em qualquer parte do mundo (CZAPSKI, 1998, p. 55).

- A EA entra em 1998 nos Parâmetros Curriculares Nacionais da educação brasileira como tema transversal (BRASIL, 1998, p. 187).

- Em 2000, realizou-se em Brasília o Seminário Nacional de Educação Ambiental reunindo várias autoridades nacionais, com o objetivo de discutir as diretrizes políticas da EA e apresentar os Parâmetros em Ação de Meio Ambiente para o ensino fundamental (DIAS, 2004, p. 71).

- Em 2012, publicou-se a Resolução n. 2, de 15 de junho de 2012, que estabelece as Diretrizes Curriculares Nacionais para a Educação Ambiental (BRASIL, 2012, p. 1), dentre outros fatos.

Exatamente pelo amadurecimento do pensamento ambiental e da legislação ambiental no Brasil, atualmente há muitas empresas públicas e privadas que desenvolvem programas, projetos e ações de Educação Ambiental, seja pela legislação, pela necessidade de dar uma resposta do ponto de vista da responsabilidade socioambiental, seja ainda por iniciativa própria. Paralelamente, tem surgido também o reconhecimento de empresas que realização tais atividades com qualidade notável por meio de eventos e premiações sobre Educação Ambiental.

É importante ressaltar que atualmente a EA é uma atividade legislada nacionalmente, utilizada na educação pública formal e tem sido extensivamente utilizada pela iniciativa privada como meio de mitigação e/ou compensação ambiental.

O Complexo Industrial Portuário Governador Eraldo Gueiros - Suape, empresa pública de direito privado do estado de Pernambuco, enquadra-se nesse perfil, pois seu Programa Básico Ambiental 17 (PBA -17), expresso no Estudo de Impacto Ambiental/ Relatório de Impacto Ambiental (SUAPE, 2000, p. 276), instituiu as diretrizes para a implantação do Programa de Educação Ambiental (PEA), como forma de promover conhecimentos ecológicos e a inclusão ambiental na área de influência direta de Suape (Cabo de Santo 
Agostinho e Ipojuca). Suape, em 2010, implantou parcialmente o PEA mediante o Programa Pedagogia Ambiental (PPA).

O PPA vem desenvolvendo atividades pedagógicas de Educação Ambiental por meio de cursos e oficinas focados na produção de conhecimentos ecológicos, ao mesmo tempo em que mobiliza pessoas para proteção, conservação, recuperação ambiental e preservação do patrimônio artístico e cultural.

Os conteúdos programáticos desenvolvidos durante os ciclos de oficinas e cursos relacionam-se com o desenvolvimento da Educação Ambiental com enfoque nas questões socioambientais globais e locais, conservação ambiental e recuperação dos recursos naturais na área de influência direta de Suape. Além disso, nas atividades educacionais do PPA, cada participante finaliza o curso elaborando um plano de ação para projetos pedagógicos ou de intervenção socioambientais, em busca de estimular a execução de tais produtos pelos alunos na comunidade onde vivem ou em sala de aula onde trabalham (PEREIRA et al., 2011, v. 2, p. 259).

Estruturaram-se essas atividades visando à realização de Cursos de Pedagogia Ambiental, voltados para a qualificação de professores e agentes ambientais, conforme os conceitos do Pnuma e as diretrizes dos Parâmetros Curriculares Nacionais (PCN), Meio Ambiente e de Ciclos de Oficinas Ecopedagógicas, cuja finalidade foi repassar as metodologias de desenvolvimento da Educação Ambiental (PEREIRA et al., 2011).

Os cursos e as oficinas organizam-se em cinco módulos de oito horas, totalizando uma carga horária de 40 horas-aulas. O material didático inclui cadernos educativos, textos de apoio, fichas de avaliação, mídias, filmes, dinâmicas de grupo, entre outros.

As atividades realizam-se no Centro de Treinamento Profissional (Cetreino) da própria empresa e em campo com visitas técnicas. Ao término de cada oficina, os participantes recebem um formulário padrão de avaliação para coleta da opinião quanto ao desempenho do curso e oficina. O formulário estrutura-se com 16 perguntas objetivas relacionadas com quatro dimensões pedagógicas: recursos didáticos, facilitador, autoavaliação e avaliação do grupo. Selecionaram-se essas perguntas por serem consideradas variáveischave dos processos de ensino-aprendizagem nos projetos pedagógicos, sendo facultada ao participante a opção de não responder a nenhuma questão.

O PPA apresenta em sua estrutura o subprojeto de Avaliação e Monitoramento visando medir sua eficiência e eficácia por meio de ferramentas específicas, e ainda estabelece indicadores que servem de parâmetros para medir e avaliar os resultados do projeto (PEREIRA et al., 2011). Porém, esse subprojeto não avaliou a influência das atividades educativas do PPA na vida profissional do seu público-alvo.

Este trabalho investigou a influência das atividades pedagógicas de Educação Ambiental por meio de cursos e oficinas executadas pelo Projeto Pedagogia Ambiental da Empresa Suape nas práticas didáticas de professores

revista brasileira educação ambiental 
dos municípios do Cabo de Santo Agostinho e Ipojuca em Pernambuco, os quais foram alunos de tais atividades educativas. Ainda foi objeto deste estudo, identificar as formas de manifestação dessa influência pelos professores que cursaram o curso e/ou a oficina.

\section{Material e métodos}

\section{Levantamento e análise de banco de dados}

Inicialmente fez-se um levantamento do banco de dados do Projeto Pedagogia Ambiental e uma seleção de dados de interesse para este trabalho. Com tais dados, produziu-se uma matriz de dados dos alunos que se inscreveram e concluíram ao menos uma das atividades educativas do Projeto Pedagogia Ambiental. Nessa matriz consolidaram-se aqueles relativos a atividade profissional, município de atuação profissional, instituição da atividade profissional e contatos (telefone, e-mail, endereço, etc.). Por meio deles, fez-se a seleção de entrevistados e o contato para os convites para a realização das entrevistas.

\section{Público-alvo, universo amostral e critérios de inclusão e exclusão}

Elaborou-se a pesquisa exclusivamente com ex-alunos do Curso de Pedagogia Ambiental ou da Oficina de Ecopedagogia que tenham concluído ao menos uma dessas atividades durante os anos de 2010 e 2011. Selecionaramse somente professores (com no mínimo graduação como titulação) da rede pública estadual de Pernambuco que atuassem em pelo menos uma turma de ensino fundamental de escolas do município de Cabo de Santo Agostinho ou de Ipojuca. Para evitar respostas em duplicidade, selecionou-se apenas um entrevistado por escola.

Qualquer pessoa enquadrada nesses parâmetros considerou-se públicoalvo e sujeito da pesquisa em potencial. Não houve distinção quanto a idade, sexo ou titulação (acima de graduação) dos participantes.

O banco de dados para a seleção de participantes foi feito com base nos dados do Projeto Básico de Educação Ambiental, Subprojeto de Avaliação e Monitoramento fornecidos pelo Centro de Integração de Projetos Sociais (Cips).

\section{Realização das entrevistas}

Após a consolidação do banco de dados e de acordo com os critérios de inclusão e exclusão da pesquisa, obteve-se um banco de dados com 60 sujeitos da pesquisa em potencial, porém apenas 15 deles se enquadravam nos critérios adotados neste trabalho, e concordaram em aceitar participar da pesquisa após a devida apresentação do objetivo do trabalho e completa segurança de sigilo de dados. 
As entrevistas realizaram-se de junho a agosto de 2010. Aplicou-se a cada entrevistado um questionário semiestruturado, com 18 perguntas divididas em três blocos: 1) Projeto Pedagogia Ambiental; 2) metodologia técnicas pedagógicas; 3 ) referenciais pedagógicos, com perguntas objetivas e subjetivas (APÊNDICE A).

A tabulação dos dados obtidos consistiu na elaboração de uma planilha do Microsoft Excel®, conversão de números absolutos em percentuais e comparação entre cada resposta a cada questão.

\section{Resultados e discussão}

Em relação a mudanças positivas nas atividades pedagógicas desenvolvidas pelos entrevistados em seu local de trabalho após a participação nos cursos do PPA, do total dos entrevistados, afirmaram 100\% que houve mudanças positivas em suas práticas pedagógicas. Esse fato pode ser atribuído a vários fatores, por exemplo, aquisição de conhecimentos e habilidades possibilitando nova percepção acerca da inter-relação do homem com o meio ambiente, inserindo a EA de forma sistematizada nas disciplinas e superando essa dentre outras dificuldades que podem ser encontradas por professores, como citam Evangelista e Vital (2013, p.150) quando listam as principais dificuldades encontradas por professores do município de Sumé, Paraíba.

À pergunta em relação ao grau de relevância das atividades pedagógicas do PPA sobre mudanças positivas em seus trabalhos, informaram $53 \%$ dos entrevistados que obtiveram média relevância, enquanto $47 \%$ citaram alta relevância. Nenhum entrevistado citou baixa ou nenhuma relevância.

Assim, os dados demonstram que os cursos e as oficinas do Projeto Pedagogia Ambiental apresentaram mudanças significantes positivamente nas atividades pedagógicas dos educadores entrevistados. Isso também apresenta importância do ponto de vista de Evangelista e Vital (2013, p.150) já que tais autores encontraram em seu trabalho professores com diversas dificuldades em realizar Educação Ambiental de forma sistematizada e integrada e que não recebiam apoio para formações complementares, como as oferecidas pelo PPA.

Sobre o desenvolvimento de alguma prática de Educação Ambiental na escola, revelaram $87 \%$ dos entrevistados que desenvolveram práticas pedagógicas sobre o tema, e apenas $13 \%$ ainda não tinham desenvolvido até 0 momento da entrevista. Esse resultado foi acima da média registrada por Pereira et al. (2011), que relata para 2011 o desenvolvimento de práticas de Educação Ambiental em $60 \%$ dos participantes. Possivelmente, essa divergência ocasionou-se por este trabalho ser direcionado a professores, o que mostra tendência para um aumento no percentual de participantes que realizaram alguma prática em sala de aula. 
Além do número de entrevistados que utilizaram práticas pedagógicas, percebeu-se que alguns dos participantes utilizaram mais de uma prática, totalizando 18 citações. Constatou-se que a prática de ensino mais adotada pelos entrevistados foram atividades de coleta seletiva seguida de técnicas pedagógicas nas escolas com o somatório de atividades que só foram citadas uma vez, que, em conjunto, denominaram-se "Outras" (Gráfico 1).

\section{Práticas pedagógicas utilizadas pelos entrevistados em sala de aula}

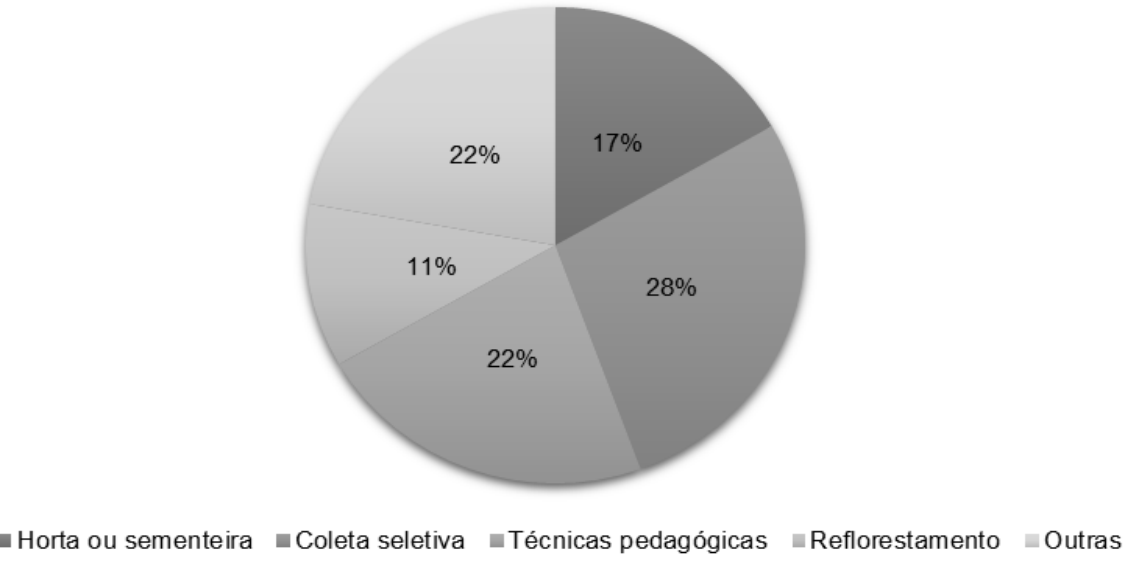

Gráfico 1: Práticas de Educação Ambiental adotadas por professores de Ipojuca e Cabo de Santo Agostinho concluintes do Curso de Pedagogia Ambiental ou a Oficina de Ecopedagogia de Suape. Fonte: Dados da pesquisa.

Possivelmente em decorrência do Projeto Pedagogia Ambiental enfatizar a necessidade de trabalhar os problemas $e$ as potencialidades da realidade local durante as práticas de Educação Ambiental na escola, afirmaram 87\% dos entrevistados que desenvolveram ações incluindo temas locais enquanto $13 \%$ não consideraram tais temas em suas atividades. Esse questionamento não tem como objetivo discutir qual dessas duas opções de temas é melhor ou mais eficaz, mas averiguar se os cursos realizados serviram não somente de estímulo para a implantação de práticas pedagógicas pelos entrevistados, mas também como diretriz diante do alto número de temas conforme instruído pelo PPA (PEREIRA et al., 2011), o que se confirmou.

Em relação aos conhecimentos adquiridos durante os cursos e oficinas, perguntou-se aos entrevistados se foi possível identificar novas temáticas, com o intento de inseri-las nas atividades de Educação Ambiental na escola. Do total de entrevistados, conseguiram identificar e inseri-las no contexto ensinoaprendizagem $66,70 \%$ enquanto $33,30 \%$ dos entrevistados não identificaram, consequentemente não inseriram novas temáticas.

As novas temáticas identificadas e inseridas nas atividades de Educação Ambiental nas escolas foram as seguintes: os impactos provenientes da degradação do manguezal; a importância da arborização; o papel da 
percepção ambiental; os princípios fundamentais das correntes pedagógicas da Educação Ambiental; aspectos gerais acerca da reciclagem, princípio dos 3 Rs e coleta seletiva (reduzir, reutilizar e reciclar); a necessidade de evitar 0 desperdício de água, papel e energia, bem como a dinâmica da limpeza.

Em relação à pergunta sobre a contribuição das técnicas aplicadas no Projeto Pedagogia Ambiental, no contexto do ensino-aprendizagem da Educação Ambiental na escola, foi possível observar que as dinâmicas se destacaram quando comparadas com as demais opções, representando $41 \%$ das respostas dos entrevistados, conforme o Gráfico 2.

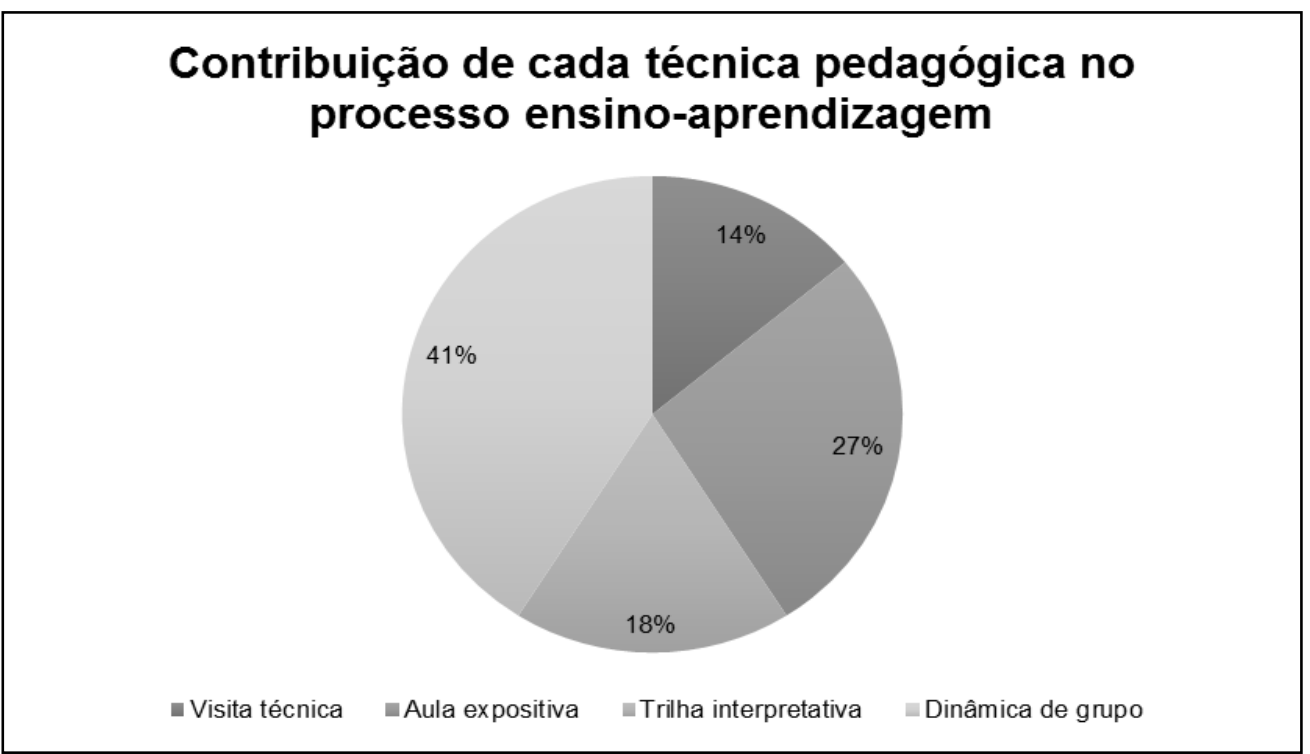

Gráfico 2: Técnicas pedagógicas utilizadas no PPA que mais contribuíram para o processo ensino-aprendizagem. Fonte: Dados da pesquisa.

Não é recente a ideia de que técnicas pedagógicas tradicionais como a aula puramente expositiva ou avaliações exclusivamente por meio de provas não são sozinhas os melhores métodos de ensino e avaliação (MCPARLAND; NOBLE; LIVINGSTON, 2004, p.859; RODRIGUES; DEMOLY, 2014, p.396). As metodologias que promovem interação e discussão têm ao longo das últimas décadas adquirido força no meio educacional não só pelo conforto que promovem aos participantes do processo ensino-aprendizagem, mas também pela sua eficácia. Os resultados aqui apresentados traduzem isso, ou pelo menos quanto à eficácia das metodologias de aulas expositivas somadas às dinâmicas de grupo, já que as duas são as mais representativas quanto à contribuição ao ensino-aprendizagem.

Quanto à relevância dos textos, vídeos e trabalhos dirigidos de grupo utilizados no PPA, apontaram $60 \%$ dos entrevistados terem sido de alta relevância sua aplicabilidade nas instituições de ensino enquanto $40 \%$ avaliaram como de média relevância. Nenhum entrevistado apontou tais ferramentas como de baixa relevância. 
Tais resultados sugerem que essas ferramentas utilizadas no PPA podem ser utilizadas por seus alunos (que também são professores) como opções interessantes para serem trabalhadas em sala de aula. É importante salientar que a utilização dessas ferramentas pode não ser somente mais eficiente, mas também pode levar mais conforto aos alunos por saírem da rotina, mas pelos alunos terem a liberdade de discutir os temas entre si, etc., conforme ressaltam Mcparland, Noble e Livingston (2004, p.859).

$\mathrm{Na}$ prática, à pergunta se foi possível obter mudanças nas escolas por meio do plano de ação desenvolvido durante a participação de cada entrevistado no PPA, assinalaram $93 \%$ que foram alcançadas mudanças importantes enquanto apenas $7 \%$ dos entrevistados não obtiveram modificações favoráveis. É importante observar que os planos de ação desenvolvidos no PPA foram de intervenções socioambientais ou pedagógicas, e essa pergunta se reporta ao somatório de entrevistados que fizeram um tipo ou outro de plano; logo, os $93 \%$ desse questionamento superam os $87 \%$ daqueles que desenvolveram exclusivamente práticas educacionais ambientais porque alguns dos entrevistados podem ter escolhido planos de ação socioambientais, o que não foi investigado aqui.

Em relação à relevância da aplicabilidade das dinâmicas utilizadas nos cursos e oficinas, constatou-se um resultado significativo, uma vez que $73 \%$ correspondem à alta relevância e $27 \%$ como média relevância. Nenhum entrevistado apontou a aplicabilidade das dinâmicas com baixa relevância. Esse é um ponto muito interessante que ratifica a importância de técnicas pedagógicas que enriqueçam o processo ensino-aprendizagem, como relatam Almeida et al. (2013, p.140) em seu trabalho, que demonstrou a importância das práticas educativas na Educação Ambiental sobre a geração de resíduos sólidos.

Perguntou-se aos entrevistados se o roteiro orientado, discutido nos cursos e oficinas, contribuiu no contexto ensino-aprendizagem na instituição de ensino. O resultado foi marcantemente acentuado, já que $87 \%$ dos sujeitos da pesquisa responderam que a construção desse roteiro colaborou na execução do projeto pedagógico.

Tais resultados sugerem que o roteiro orientado bem formulado tornouse para os alunos do PPA um mecanismo de grande interesse por fornecer subsídios durante os processos de planejamento, implantação e gerenciamento; além de delimitar as estratégias, identificando as possíveis soluções da problematização.

À pergunta sobre a motivação que os cursos e as oficinas tinham provocado na possibilidade do desenvolvimento de práticas pedagógicas na escola onde cada um trabalha, responderam $100 \%$ dos entrevistados que se sentiram motivados a desenvolver projetos de Educação Ambiental no respectivo local de trabalho.

Questão interessante é que, mesmo todos os entrevistados tendo saído 
pedagógicos na respectiva escola, declararam $13 \%$ não terem realizado nenhuma atividade até o momento da entrevista.

No que se refere à aplicação do Ciclo de Aprendizagem Vivencial (CAV) abordado no Projeto Pedagogia Ambiental (PEREIRA et al., 2011), verificou-se que apenas $40 \%$ utilizaram esse método para desempenhar práticas educativas voltadas à questão ambiental na escola enquanto $60 \%$ não o empregaram. Esses resultados refletem a dificuldade dos professores entrevistados em desenvolver novas metodologias diante do ambiente escolar convencional.

Seguiu-se com a pergunta se os professores entrevistados envolveram professores de outras áreas na atividade de Educação Ambiental na instituição de ensino onde trabalham. Do total de entrevistados, relataram $80 \%$ que desenvolveram as atividades com outros professores que atuam com outras disciplinas, não envolveram profissionais de outras disciplinas $7 \%$ e não desenvolveram nenhuma atividade $13 \%$ como verificado anteriormente.

Desse modo, esses resultados estabeleceram um cenário favorável para a ratificação da proposta do PPA em virtude de fomentar práticas interdisciplinares e transdisciplinares, propiciando mudanças ou rupturas das práticas pedagógicas centradas em apenas uma disciplina.

Os conceitos do Pnuma abordados no PPA possibilitaram meios de reflexão e consequentemente trouxeram mudanças benéficas nas atividades de Educação Ambiental nas escolas, o que se confirmou por $87 \%$ dos professores entrevistados. Esse resultado apresentou um nível satisfatório, pois apenas $13 \%$ afirmaram que os conceitos do Pnuma não permitiram tais reflexões e mudanças.

Por fim, sobre os Parâmetros Curriculares Nacionais, consideraram as orientações contidas nos PCN para elaboração das práticas de Educação Ambiental desenvolvidas nas escolas $87 \%$ dos educadores entrevistados. Por outro lado $13 \%$ não consideraram essas orientações. Esse quadro demonstra um avanço para a reorganização da Educação Ambiental nas escolas onde trabalharam quanto à implementação da educação como tema transversal, preconizado pelos PCN.

\section{Conclusões}

Notoriamente, o PPA foi importante para a melhoria na vivência profissional dos participantes das atividades pedagógicas de Educação Ambiental por meio de cursos e oficinas executadas pelo Projeto Pedagogia Ambiental do Complexo Industrial Portuário Governador Eraldo Gueiros Suape, no tocante à diversificação de técnicas, métodos e abordagens quanto à Educação Ambiental. Uma prova disso é a demonstração de resultados favoráveis nas questões analisadas.

A melhoria e implementação de práticas de Educação Ambiental nas escolas públicas onde trabalham os entrevistados é ponto importante na busca

revista brasileira educação ambiental 
por uma educação pública com excelência. Porém, desperta ao mesmo tempo uma grande preocupação, já que $87 \%$ dos profissionais entrevistados necessitaram participar de pelo menos um curso complementar de curta duração para utilizarem artifícios alternativos e didaticamente interessantes na Educação Ambiental em sala de aula, o que sugere que a formação acadêmica não forneceu subsídio ou não despertou o interesse por tal postura dos educadores.

Logicamente, isso necessita ser investigado posteriormente, porém é preocupante desde já. Ao mesmo tempo, ressalta-se a importância das atividades do PPA para a educação formal pública nos municípios de Cabo de Santo Agostinho e Ipojuca. Tal importância fortifica-se quando 93\% dos entrevistados afirmaram que houve mudanças positivas significativas em sua turma por meio dos conhecimentos adquiridos no PPA.

Ressalta-se a importância da junção entre as aulas expositivas e dinâmicas coletivas apontadas pelos entrevistados como as opções mais eficazes no processo ensino-aprendizado. Tal fato corrobora a ideia da junção de metodologias pedagógicas tradicionais e metodologias participativas em que o professor se torna um mediador para o amadurecimento do saber pelos alunos.

Por fim, é necessário ressaltar que as atividades do PPA visam colaborar na formação profissional e estimular a elaboração e execução de projetos de pedagogia ambiental e/ou de intervenção socioambiental.

Este trabalho teve como foco de investigação somente os projetos pedagógicos ambientais desenvolvidos por ex-alunos do PPA em escolas públicas dos municípios do Cabo de Santo Agostinho e Ipojuca, logo o número total efetivo de sucesso nesse item para o PPA pode superar os $87 \%$ observados neste trabalho.

\section{Referências}

ALMEIDA, E.M.P.; MONTANHA, S.M.; SANTANA, P.M.C.; SOARES, L.C.B. Educação Ambiental na escola: estudo da relação entre alimentação e produção de resíduos. Revbea, Rio Grande, v. 8, n. 2, p. 131-149, 2013.

BRASIL. Ministério da Educação. Conselho Nacional de Educação. Conselho Pleno. Resolução n. 2, de 15 de junho de 2012. Brasília, 2012.

BRASIL. Ministério do Meio Ambiente, Diretoria de Educação Ambiental; Ministério da Educação, Coordenação Geral de Educação Ambiental. Programa Nacional de Educação Ambiental - ProNEA. 3. ed. Brasília, 2005.

BRASIL. Secretaria de Educação Fundamental. Parâmetros Curriculares Nacionais: terceiro e quarto ciclos: apresentação dos temas transversais / Secretaria de Educação Fundamental. Brasília : MEC/SEF, 1998.

CZAPSKI, S. A implantação da Educação Ambiental no Brasil. Brasília: Ministério da Educação e do Desporto, 1998.

Revbea, São Paulo, V. 12, № 2: 318-330, 2017. 
DIAS, G. F. Educação Ambiental: princípios e práticas. 9. ed. São Paulo: Gaia, 2004.

EVANGELISTA, M.A.A.; VITAL, A.F.M. Visão dos professores da rede pública estadual de Sume (PB) sobre as dificuldades na condução de ações em Educação Ambiental. Revbea, Rio Grande, v. 8, n. 2, p. 150-163, 2013.

JACOBI, P. Educação Ambiental, cidadania e sustentabilidade. Cadernos de Pesquisa, São Paulo, v. 118, p. 189-205, mar. 2003.

MCPARLAND, M.; NOBLE, L.M.; LIVINGSTON, G. The effectiveness of problem-based learning compared to traditional teaching in undergraduate psychiatry. Medical Education, v. 38, n. 8, p. 859-867, Aug. 2004.

MORAES, S.; CLAUZET, M.; RAMIRES, M.; BARRELLA, W. Patrimônio cultural da Estação Ecológica Juréia Itatins - Núcleo Arpoador, Peruíbe, SP, Brasil: as estórias tradicionais. UNISANTA Humanitas, Santos, v. 1, n. 2, p. 94-98, 2012.

MURPHY, P.C. What a book can do: the publication and reception of Silent Spring. Massachusetts: University Massachusetts Press, 2005.

PEREIRA, S.M.; BEZERRA, A.P.X.G.; SOUZA, A.R.L.; CIRILO, A.M.; ZAPONI, J.R.C.; OLIVEIRA, L.R.V. et al. Relatório anual 2011: projeto pedagogia ambiental/PEA-Suape. Recife: Itep, 2011. 2 v.

RODRIGUES, M.D.F.; DEMOLY, K.R.A. O jogo da areia como ferramenta na Educação Ambiental. Revbea, São Paulo, v. 9, n. 2, p. 395-411, 2014.

SUAPE. EIA: Estudo de impacto ambiental do Projeto de Ampliação e Modernização do Porto de Suape. Recife, 2000. v. 5. 


\section{APÊNDICE A - Questionário}

Bloco I - PROJETO PEDAGOGIA AMBIENTAL

1. Você considera que sua participação no Projeto Pedagogia Ambiental, oferecido por Suape, resultou em mudanças positivas nas atividades pedagógicas de Educação Ambiental em sua escola? ( ) Sim ( ) Não

3. Em caso afirmativo, em que nível de relevância o Projeto Pedagogia Ambiental provocou mudanças positivas na Educação Ambiental em sua instituição de ensino?

Alta relevância ( ) Média relevância ( ) Baixa relevância ( )

4. Após o término do curso e da oficina do Projeto Pedagogia Ambiental, você desenvolve ou desenvolveu alguma prática de Educação Ambiental na escola? ( ) Sim Não

5. Em caso afirmativo à resposta anterior, quais das opções abaixo?

$\begin{array}{ll}\text { ( ) Horta ou Sementeira } & (\text { ) Coleta Seletiva } \\ \text { ( ) Técnicas Pedagógicas } & (\text { ) Reflorestamento }\end{array}$

6. Depois da participação nos cursos e oficinas, são enfatizados os problemas e as potencialidades da realidade local durante as práticas de Educação Ambiental em sua escola? Sim ( ) Não ( )

7. Com os conhecimentos adquiridos, no Projeto Pedagogia Ambiental, você conseguiu identificar novas temáticas, com a finalidade de inseri-las nas atividades de Educação Ambiental na escola? Sim( ) Não( )

8. Em caso afirmativo à questão anterior, qual(quais) temática(s)?

\section{BLOCO II - METODOLOGIA - TÉCNICAS PEDAGÓGICAS}

9. Qual técnica aplicada no Projeto Pedagogia Ambiental contribuiu para o contexto ensino-aprendizagem da Educação Ambiental em sua escola?

$\begin{array}{lll}\text { ( ) Visita Técnica } & (\text { ) Aula Expositiva } \\ \text { ( ) Trilha Interpretativa } & (\text { ) Dinâmica } & (\quad) \text { Roda } \\ \text { ( ) Outros: } & & \end{array}$

10. Os textos, vídeos e trabalhos dirigidos de grupo abordados no curso e na oficina foram empregados nas atividades pedagógicas desenvolvidas na sua escola?

Alta relevância ( ) Média relevância( ) Baixa relevância ( )

11. O plano de ação de Educação Ambiental desenvolvido nos cursos e oficinas possibilitou mudanças favoráveis na sua instituição de ensino? Sim ( ) Não ( )

12. Que avaliação você faz das dinâmicas utilizadas nos cursos e oficinas, quanto à relevância delas para aplicabilidade na sua escola? Alta relevância ( ) Média relevância ( ) Baixa relevância ( )

13. O roteiro orientado discutido nos cursos e oficinas contribuiu para a execução dos projetos pedagógicos na sua instituição de ensino? Sim ( ) Não ( )

14. Após a participação no Projeto Pedagogia Ambiental, você se sentiu motivado para atuar em projetos de Educação Ambiental? Sim ( ) Não ( )

15. Você utiliza o Ciclo de Aprendizagem Vivencial (CAV) abordado no Projeto Pedagogia Ambiental para desempenhar práticas educativas voltadas à questão ambiental na sua escola? $\operatorname{Sim}()$ Não ( )

\section{BLOCO III - REFERENCIAIS PEADAGÓGICOS}

16. Em relação à transdisciplinaridade e interdisciplinaridade abordadas no curso e oficina, existem ou existiram outros professores envolvidos na sua atividade de Educação Ambiental na escola? Sim ( ) Não ( )

17. A discussão dos conceitos de Educação Ambiental baseado no Pnuma, no curso e oficina, permitiu reflexões e mudanças benéficas para o processo de ensino-aprendizagem da Educação Ambiental na sua instituição de ensino? Sim ( ) Não ( )

18. Na elaboração das práticas de Educação Ambiental em sua escola, você considera as variáveis contidas nos Parâmetros Curriculares Nacionais (PCN), discutidas ao longo do curso e da oficina? $\operatorname{Sim}($ ) Não ( )

Revbea, São Paulo, V. 12, № 2: 318-330, 2017. 